\title{
Towards POLLUTION 2000+
}

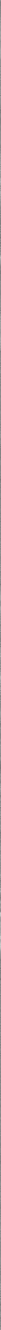





\title{
Proposal to the IWC on furthering the recommendations of the Pollution Workshop*
}

\author{
Members: Aguilar, Bjorge. Donovan, Reijnders.
}

\section{INTRODUCTION}

The Group met in Texel, the Netherlands, on 3 July 1997 to discuss ways to further the recommendations given in the Bergen Pollution Workshop report as agreed by the Scientific Committee at the 48th Annual Meeting in Aberdeen. Prime consideration was given to Recommendation 1 of that report which in effect summarised the whole meeting. The section in the report leading to that recommendation stated:

The Workshop believes that there are sufficient data on the adverse effects of pollutants on the health of other marine mammal and terrestrial species to warrant concern for cetaceans. However, the report and its recommendations show that a considerable amount of fundamental research is needed before it will be possible to adequately address the question of the effects of chemical pollutants on all cetaceans.

Notwithstanding the cautionary note that it is often not appropriate to extrapolate from one species to another, it is clear that if any progress is to be made within a reasonable timeframe, a multidisciplinary, multinational focused programme of research is required that concentrates on those species/areas where there is most chance of success. The Scientific Committee (and the Commission) is strongly urged to consider ways to facilitate the development and execution of such research.

Three species are considered particularly suitable: the bottlenose dolphin; the harbour porpoise; and the beluga.

The rationale behind Recommendation 1 is detailed in the Workshop report. It should be noted that by concentrating on this recommendation and its focal species, the group is not implying that research on other species should not be carried out.

Indeed it is hoped that the approach outlined in this proposal may prove useful to researchers working on other species. In particular, with respect to baleen whales, it was noted (O'Shea and Brownell, 1994) that levels of pollutants are low in baleen whales and much below threshold levels presently considered to elicit adverse effects in mammals. Therefore, baleen whales are at this stage not considered suitable priority species to establish the sought cause-effect relationship between cetacean health and chemical pollution. However, the work in progress on North Pacific minke whales (Fujise, pers. comm.) appears promising and further work and presentation of results is encouraged.

\section{OBJECTIVES}

In an ideal world, the ultimate objective of pollution studies for cetacean management is to determine a predictive model linking tissue pollutant levels with effects at the population level. This is clearly not a realistic short-term goal but it might be achievable in the long-term. Given the wide variety of factors influencing the population dynamics of cetaceans (and indeed any organism), then at best one might eventually be in a position to assign some level of probability of certain effects occurring at the population level, given certain levels of specific pollutants in the body.

* Also printed in Rep. int. Whal Commn 48:425-8 [1998]. 


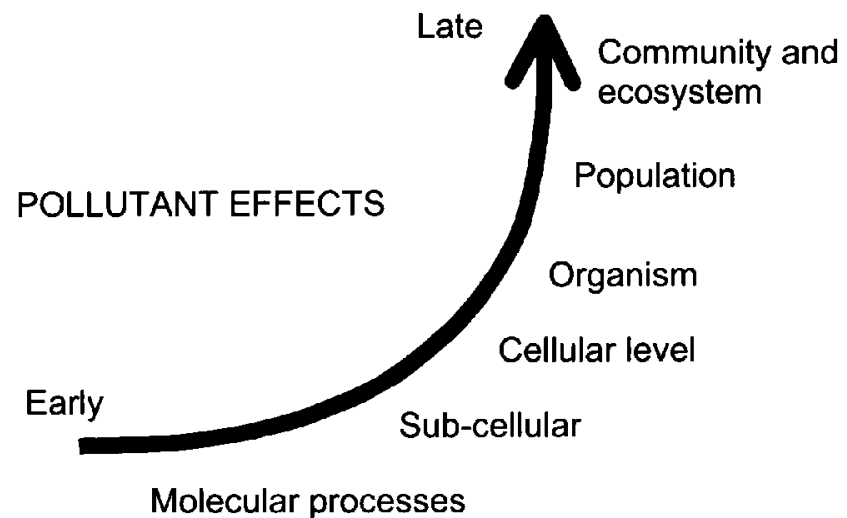

Fig. 1. General action of pollutants.

The general action of pollutants follows the pattern in Fig. 1.

The primary aim of the following proposal is to investigate the first links in the chain, i.e. attempting to determine the relationship between levels in certain tissues and indicators of certain effects. It seemed appropriate to focus on two sets of pollutants: (1) that might provide information of more general applicability, e.g. impact of organochlorines: and (2) that are subject to more local interpretation such as impact of heavy metals. For the latter there are additional complications to their natural high level occurrence in some regions as well as very local high concentrations. It was agreed to focus under (1) on the PCBs for a number of reasons but primarily because more is known about their uptake and metabolisation, as well as the existence of available techniques to indicate exposure and effect.

The process of decision making should follow the path as shown in Fig. 2.

\section{SOURCES OF SAMPLES}

Suitable samples can be obtained from several sources:

(1) biopsy from free-ranging animals;

(2) captive animals;

(3) temporarily live-captured animals;

(4) by-caught animals;

(5) legally harvested animals.

Not all of the above can provide suitable samples for all of the analyses. Table 1 summarises this applicability.

\section{ASSOCIATED BIOLOGICAL INFORMATION}

It is clear from the Workshop report that interpretation of the significance of pollutant levels requires knowledge of the sampled animal. Those variables that are particularly important for certain analyses are highlighted in Table 1 . In addition, although we are concentrating on the first links of the chain of pollutant-induced effects, it is important to look for certain pathological conditions, especially those that may be associated with pollutants. In cases where sample source allows for detailed pathology, it is considered of relevance that 


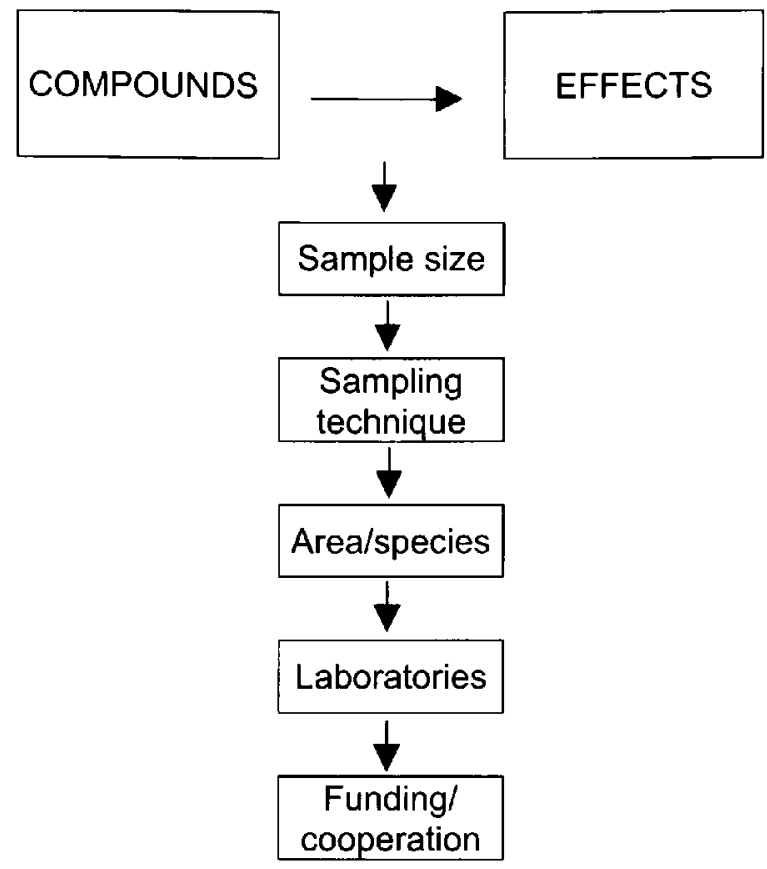

Fig. 2. The decision-making process.

comprehensive pathology is carried out. The Workshop recommendations provide further details but it is clear that changes related to the reproductive system are particularly important.

The following information should be collected for each sampled animal.

(1) Position of capture.

(2) Time of capture/estimated post-mortem time.

(3) Age (teeth), length, sex.

(4) Reproductive condition: collect ovaries, testes samples. Collect whole foetuses and newborn calves where feasible.

(5) Nutritional condition.

(6) Pathology: occlusions and stenosis, collect adrenals, testes, histological liver samples (ribosome density for comparison with enzyme induction).

\section{INDICATORS}

There are a number of studies in which indicators for pollution exposure and effect are identified. We have focused on eight that we believe hold most promise for cetacean studies (Table 1). The nature of the samples that can be used for each indicator are given. There are some analytical techniques still under development for particular tissues.

In this regard we recommend that an early part of the project should comprise a calibration study to examine: post-mortem times, storage methods and storage times.

With respect to metallothioneins, the Workshop had suggested further investigation of their potential as indicators (Workshop report, item 5.4). This project will allow this to happen. 


\section{AREA/SPECIES}

The Workshop had recommended three focal species which fit well for the PCB studies. We looked at these and tried to identify areas that fulfilled the gradient criterion and where it appeared that reasonable sample sizes could be obtained at least in principle (Table 2).

The Workshop had not commented on focal species/areas for heavy metal analysis. However, we believe that rivers subject to intensive mining operations which determine 'clean' and 'polluted' stream segments would be ideal. For example, in the Amazon river the upper stream is expected to carry only a light heavy metal load whereas parts of the lower river near gold and silver mines are known to be heavily polluted with mercury. The Amazon river dolphin inhabits both the upper and lower parts of the river, and despite being known in some cases to move along considerable distances, appears to occur in essentially local populations. They thus present an excellent subject for studying response variation to differential heavy metal exposure in a relatively homogeneous genetic population. Temporary live-capture of free-ranging individuals is possible.

\section{Table 1}

Pollutants and effect indicators to be studies in different cetacean tissues, including feasibility of biopsy sampling and identified potential coordinating/participating laboratories. Key: $1=$ Feasible; $2=$ Potentially feasible; 3 = Dubious; $4=$ Infeasible. $\mathrm{A}=$ Age; $\mathrm{S}=$ Sex; $\mathrm{N}=$ Nutritive condition. $\mathrm{GL}=\mathrm{Goksøyr}$ lab.; IBN = Institute for Forestry and Nature Research; LUW = Agriculture Univ. of Wageningen (Toxicology Dept.); $\mathrm{ML}=$ Martineau lab.; UB = Univ. of Barcelona; US = Univ. of Sienna; UU = Univ. of Utrecht; $\mathrm{WH}=$ Woods Hole Oceanographic Institute; WL = Wagemann lab.; YL = Yoshioka lab. .

\begin{tabular}{|c|c|c|c|c|c|c|c|}
\hline & \multirow{2}{*}{$\begin{array}{l}\text { Potential } \\
\text { tissues }\end{array}$} & \multirow[b]{2}{*}{ Biopsies } & \multicolumn{2}{|c|}{ Post mortem } & \multirow{2}{*}{$\begin{array}{l}\text { Captive } \\
\text { animals }\end{array}$} & \multirow[b]{2}{*}{ Variables } & \multirow[b]{2}{*}{ Laboratories } \\
\hline & & & $24-3 \mathrm{hr}$ & $<3 \mathrm{hr}$ & & & \\
\hline \multicolumn{8}{|l|}{ Pollutants } \\
\hline \multirow[t]{2}{*}{ PCBs } & Blubber & 1 & 1 & 1 & 1 & S. A, N & UB, IBN \\
\hline & Blood & 4 & 3 & 1 & 1 & S. A, N & UB. IBN \\
\hline \multirow[t]{2}{*}{$\mathrm{Hg}$, met-Hg } & Skin & 1 & 1 & 1 & 1 & A. S & ICES group \\
\hline & Liver & 4 & 1 & 1 & 4 & A. $S$ & ICES group \\
\hline \multirow[t]{2}{*}{ Cadmium } & Skin & 1 & 1 & 1 & 1 & $A, S$ & ICES group \\
\hline & Kidncy & 4 & 1 & 1 & 4 & $A, S$ & ICES group \\
\hline \multicolumn{8}{|l|}{ Indicators } \\
\hline \multirow[t]{2}{*}{ Enzyme induction } & Liver & 4 & $1 *$ & 1 & 4 & S. A & LUW, US, WH, GL \\
\hline & Skin & $1^{*}$ & $1^{*}$ & $1^{*}$ & $1^{*}$ & $\mathrm{~S}, \mathrm{~A}$ & LUW, US, WH, GL \\
\hline Sex hormones & Blood & 4 & 2 & 1 & 1 & $\mathrm{~S}, \mathrm{~A}$ & IBN, Hospitals \\
\hline (oestradiol, testosterone & Muscle & 3 & 2 & 1 & 2 & S. A & YL \\
\hline progesterone) & Blubber & $1^{*}$ & $2 *$ & $1^{*}$ & $1^{*}$ & S. A & $?$ \\
\hline \multirow[t]{3}{*}{ Vitamin A } & Blood & 4 & 1 & 1 & 1 & $?$ & LUW, UB \\
\hline & liver & 4 & 1 & 1 & 4 & $?$ & LUW. UB \\
\hline & Skin & $1^{*}$ & $1^{*}$ & $1^{*}$ & $1 *$ & $?$ & LUW, UB \\
\hline \multirow[t]{2}{*}{ Thyroid hormones } & Blood & 4 & 4 & 1 & 1 & & LUW \\
\hline & Liver & 4 & 4 & 1 & 4 & S. A & LUW \\
\hline \multirow[t]{2}{*}{ DNA adducts } & Skin & 1 & 1 & 1 & 1 & $\mathrm{~A}$ & ML.UU \\
\hline & Liver & 4 & 1 & 1 & 4 & $\mathrm{~A}$ & ML, UU \\
\hline \multirow[t]{2}{*}{ Porphyrines } & Liver & 4 & 2 & 1 & 4 & $?$ & UB. IBN \\
\hline & Skin & $1^{*}$ & $2^{*}$ & $1^{*}$ & $1^{*}$ & $?$ & UB, IBN \\
\hline \multirow[t]{3}{*}{ Luciferase } & Blubber & 1 & 1 & 1 & 1 & $?$ & LUW \\
\hline & Skin & 1 & 1 & 1 & 1 & $?$ & LUW \\
\hline & Blood & 4 & 1 & 1 & 1 & $?$ & LUW \\
\hline Metallothioneins & Liver & 4 & $?$ & 1 & 4 & A & LUW,WL \\
\hline Histopathology & Liver & 4 & 2 & 1 & 4 & A & LUW,WL \\
\hline
\end{tabular}

\footnotetext{
* Analytical technique under development.
} 
Table 2

State of knowledge on cetacean species in specific areas over a pollution gradicnt, and sampling methods to study pollutant impact.

\begin{tabular}{|c|c|c|c|}
\hline Sp./pollution level & Study arca & Sample source & State of knowledge \\
\hline \multicolumn{4}{|l|}{ Bottlenose dolphins } \\
\hline \multirow[t]{3}{*}{$\mathrm{High} /$ medium } & Florida & Temporary live-capture & $\begin{array}{l}\text { V. well-studied already, assoc. } \\
\text { biological info. available }\end{array}$ \\
\hline & Moray Firth & Biopsy sampling & $\begin{array}{l}\text { Small population, some assoc. } \\
\text { biological information available }\end{array}$ \\
\hline & Mediterranean & Biopsy sampling & $\begin{array}{l}\text { Large population, no assoc. } \\
\text { biological info. }\end{array}$ \\
\hline Light & Mauritania & Biopsy sampling & As above \\
\hline \multicolumn{4}{|c|}{ Harbour porpoises } \\
\hline \multirow[t]{2}{*}{ High/medium } & Gulf of Maine/Bay of Fundy & Bycatch $(c a 1800)$ & Studies underway on bycatch \\
\hline & North Sea & Bycatch (several 000 s) & As above \\
\hline \multirow[t]{2}{*}{ Light } & North Norway & Bycatch & \\
\hline & Greenland & Directed aboriginal hunt & Ease of collecting samples? \\
\hline \multicolumn{4}{|l|}{ White whales } \\
\hline High & Gulf of St Lawrence & Stranded & Studies underway \\
\hline \multirow[t]{2}{*}{ Light } & Canadian Arctic & Directed aboriginal hunt & Studies underway \\
\hline & Alaska & Directed aboriginal hunt $(400)$ & Studies underway \\
\hline \multirow{2}{*}{$\begin{array}{l}\text { Amazon River } \\
\text { dolphins }\end{array}$} & Amazon River & Live capture & Studies underway \\
\hline & . & Biopsy sampling & \\
\hline
\end{tabular}

\section{SAMPLE SIZE}

It is not possible at this stage to carry out a statistical prediction of the number of samples likely to be necessary to detect significant differences. However, it is clear that sample sizes will probably need to be at least 50 in each 'cell' where the cell will vary by the important variables (e.g. age and sex) as indicated in the table. The total sample needed to collect sufficient animals in each cell will depend on a number of 'sampling selectivity' factors (e.g. are juveniles more likely to be bycaught and do hunters select for larger individuals?) and of course any sex/age segregation in distribution. This needs to be examined in the planning meeting recommended below.

\section{LABORATORIES}

We recognise that if this project is to succeed it will require the involvement of a number of specialist laboratories. In Table 1 we have given a preliminary list of laboratories/co-ordinators that we know specialise in certain techniques. It is important to remember that while cost is, of course, a factor to be taken into consideration, it is vital that only recognised institutes are involved.

\section{FUNDING/CO-OPERATION}

It is clear that the cost of this project will be very large although as yet we are not in a position to estimate costs. It is also clear that this will be a multi-year, multi-institution programme. The initial stages will require identifying likely co-operating organisations/institutes/funding agencies. It is unlikely that the IWC alone will be able to fund the whole project! 
The example laboratories in Table 1 provide a starting list for collaborative institutions and they can also be approached to see if they are prepared to offer funding 'in kind', e.g. carry out analyses at 'cost' or reduced rates.

We suggest that a number of organisations could be approached for funding/moral support, e.g. ASCOBANS (Eastern North Atlantic harbour porpoises); NAMMCO (Norwegian and Greenlandic harbour porpoises); JCCM (Greenlandic and Canadian white whales); ABWC (Alaskan white whales); ICES; UNEP; IUCN.

\section{ORGANISATION}

We recommend that the first stage is to organise a planning meeting of interested Institutes and experts. We suggest that the Scientific Committee establishes a working group to further this work. One option is that the group is comprised of the four of us (Reijnders as chief co-ordinator plus Aguilar, Bjørge and Donovan). A first task will be to liaise with the relevant people to clarify the details in Table 1, both from the point of view of sample collection and analyses. A suggested list of tasks and a preliminary list of items to be discussed at the meeting are given below. We recommend that the IWC funds this part of the process alone to ensure that progress is made in a timely fashion.

In addition it is clear that the project itself will require an overall co-ordinator/co-ordinating body as it is probable that the project will comprise a number of sub-projects. While the details should probably be finalised at the planing meeting, Reijnders has agreed that he would be prepared to undertake this onerous task.

Finally, we believe that guidelines for timing and publication be agreed early in the process. Given the leading role we would expect the IWC to take we believe it is appropriate to recommend that the resultant papers be published in an IWC Special Issue. It will include an overview of the whole project with an agreed authorship followed by papers for each of the sub-projects.

It is difficult to draw up a realistic time frame for the completion of the project at this stage, as it is dependent on a number of financial and other factors, but we would expect it will take up to five years before publication of the results.

\section{ACTION}

If this project is to progress beyond the dreaming stage, it is important that a planning meeting is held to develop a fully-fledged proposal. For such a meeting to succeed, a steering group needs to be established as noted under Item 10 . We have identified a number of tasks that need to carried out before such a meeting.

(1) Contact institutions that might be interested in collaborating in analyses (i.e. refine the 'Laboratory' column in Table 1) - assigned to Reijnders and Aguilar.

(2) Contact organisations that might be interested in collaborating in data collection (i.e. refine Table 2) - assigned to Donovan and Bjørge.

(3) In the light of (1) and (2) decide if any additional expertise is required - assigned to the Steering Group.

(4) Draw up a list of invited participants - assigned to the Steering Group.

(5) Determine a draft Agenda - assigned to the Steering Group. It will be necessary to request papers on specific topics from certain of the participants. 
(6) Determine the logistics of the meeting - Aguilar has indicated that he will be prepared to host the meeting in Barcelona. It might be possible to host the meeting before the next Scientific Committee meeting but this will have to be determined by the Steering Group in the light of points (1)-(4) above. In any event it will be held in the Commission's financial year ending 31 August 1998. The estimated cost of such a meeting is $£ 15,000$.

\section{REFERENCE}

O'Shea. T.J. and Brownell, R.L. 1994. Organochlorine and metal contaminants in baleen whales - a review and eviluation of conservation implications. Sci. Total Environ. 154(2-3):179-200. 